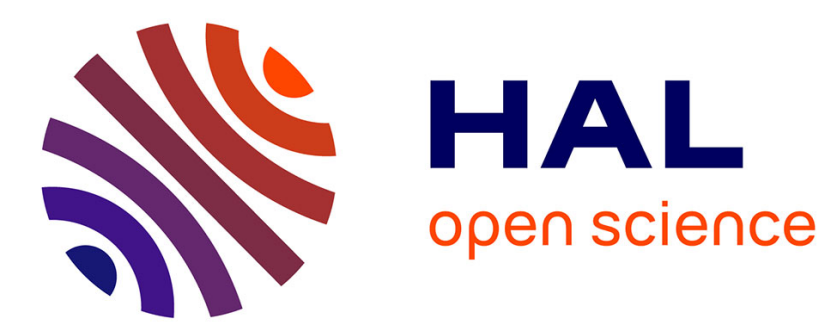

\title{
Praise the Bridge that Carries You Over: Testing the Flattery Citations Hypothesis
}

Tove Faber Frandsen, Jeppe Nicolaisen

\section{To cite this version:}

Tove Faber Frandsen, Jeppe Nicolaisen. Praise the Bridge that Carries You Over: Testing the Flattery Citations Hypothesis. Journal of the American Society for Information Science and Technology, 2011, In press. hprints-00560164

HAL Id: hprints-00560164

https://hal-hprints.archives-ouvertes.fr/hprints-00560164

Submitted on 27 Jan 2011

HAL is a multi-disciplinary open access archive for the deposit and dissemination of scientific research documents, whether they are published or not. The documents may come from teaching and research institutions in France or abroad, or from public or private research centers.
L'archive ouverte pluridisciplinaire HAL, est destinée au dépôt et à la diffusion de documents scientifiques de niveau recherche, publiés ou non, émanant des établissements d'enseignement et de recherche français ou étrangers, des laboratoires publics ou privés. 
Preprint of an article published in Journal of the American Society for Information Science and Technology.

\title{
Praise the Bridge that Carries You Over:
}

\section{Testing the Flattery Citations Hypothesis}

\author{
Tove Faber Frandsen* and Jeppe Nicolaisen**
}

* Associate professor, University of Southern Denmark, Campusvej 55, DK-5230 Odense M, DENMARK, tofr@litcul.sdu.dk

** Associate professor, Royal School of Library and Information Science, Birketinget 6, DK-2300 Copenhagen S., DENMARK, ini@iva.dk

\section{ABSTRACT}

Flattery citations of editors, potential referees, etc. has been claimed to be a common strategy among academic authors. From a sociology of science perspective, as well as from a citation analytical perspective, it is both an interesting claim and a consequential one. The paper presents a citation analysis of the editorial board members entering American Economic Review from 1984 to 2004 using a citation window of 11 years. In order to test the flattery citations hypothesis further we have conducted a study applying the difference-in-difference estimator. We analyse the number of times the editors and editorial board members of the American Economic Review were cited in articles published in the journal itself as well as in a pool of documents comprising of articles from Journal of Political Economy and Quarterly Journal of Economics. The results of the analyses do not support the existence of a flattery citation effect.

\section{INTRODUCTION}

Scientific tradition requires that scientists, when documenting their research, refer to earlier works, which relate to the subject matter of their reported work. These bibliographic references are supposed to identify those earlier researchers whose concepts, theories, methods, equipment, etc. inspired or were 
used by the author in the process of conducting and presenting his or her research (Weinstock, 1971). Bibliographic references may, however, be exploited for other purposes. One of the alleged purposes that have been brought up repeatedly is flattery. P.O. Seglen has often claimed that flattery citations of editors, potential referees, etc. is a common strategy among academic authors - at least common enough to be mentioned time and again (e.g., Seglen 1992; 1997; 1998). This is an interesting claim, and one, which if true, seem to have great consequences for various theories about the sociology of science, and of course for the practical use of citation analysis. But is it really true? Seglen himself makes no attempts to back it up by examples, by empirical evidence, nor by references to others. It is, however, a claim that can be investigated empirically. One way to do this would be to investigate whether editors, members of editorial boards and/or referees at certain journals are frequently over-cited in those journals compared to their citation rates in comparable journals. A positive result could at least indicate that the flattery citations hypothesis had something going for it. A negative result would, on the other hand, seem to falsify it right away. Currently, only two studies have tested the flattery citations hypothesis. The first is a small-scale study of the quality control of a single journal in the field of Economics (Laband, Tollison \& Karahan, 2002). The other study is a larger study that tests the flattery citations hypothesis in four Library and Information Science (LIS) journals (Frandsen \& Nicolaisen, 2010).

Laband, Tollison and Karahan (2002) investigate the citations to editors and board members of the American Economic Review (AER) by articles appearing in the AER. These results are then compared with the rate of citations to the same editors and board members in a control group of articles appearing in two comparable Economics journals. The comparisons of citation rates in 1985-1995 are mixed, and no general pattern of over-citation can be found. The final year analysed, 2000, is however, remarkable as it shows a four times greater rate of citations from AER articles than from articles in the control group. Laband, Tollison and Karahan (2002: 326-327) use the increased citations to calculate the value of being a member of editorial board:

"[A]ssume that members of the AER editorial board receive approximately 2.5 additional references in the AER than these same individuals receive in the other top general interest journals. Assume further that the level of rent seeking that occurred in 2000 continues at a constant level (although the trend is upwards). In this case an individual serving a 5-year term on the AER's board would pick up 12-13 cites in the AER over and above what (s)he could be expected to accrue otherwise. By itself, this surely creates a salary premium, 
probably on the order of 10-20 percent in base salary, especially since AER citations are more valuable than most other citations to an economist. Assume the following scenario. There is a 10 percent earnings effect. The individual editor has a base salary of $\$ 100.000$, started to work on the editorial board at age 45, and served a 5-year term. At age 50 let the returns from marginal references kick in. The individual works until age 66 and then collects a pension worth half his salary. Applying a discount rate of 2.5 percent (equal to the rate of inflation so that these two cancel out) and letting the individual live to age 80 , the cumulative value of the marginal references in this case is $\$ 240.000$. At a 5 percent premium the additional references are worth $\$ 20.000 . "$

The calculation of the value of references would preferably include a discussion of whether flattery citations are of equal value to regular citations but leaving that a side for the moment, Laband, Tollison and Karahan (2002) conclude that being an editor or member of board is of great value for the individual scholar also financially. The authors stress that there are other avenues for rent seeking behavior by authors and that rent seeking motives seem to play a relatively small role in the quality control process in economics.

The second study by Frandsen and Nicolaisen (2010) tests the flattery citations hypothesis in four selected LIS journals (Journal of Documentation; Journal of Information Science; Journal of the American Society for Information Science (and Technology); Library \& Information Science research). The results do not unambiguously show a tendency to give flattery citations to editors and members of editorial boards in these four journals. Furthermore, any potential effect is found to be irrelevant as the difference in citations is negligible.

Both studies are highly dependent on the choice of journals as reference samples. It is important that the selected journals are representative for their discipline in order to be able to generalise the results. Furthermore, it is crucial that the journals are general as highly specialised journals cannot be expected to cite each other frequently.

The development of reliable estimates of the potential citation benefit from being an editor or member of editorial board begins with the specification of a causal hypothesis or hypotheses. As is the case with any study analysing the effect of a treatment or experiment, Greenstone and Gayer (2009) argue that the key features of a causal hypothesis are that it contains a manipulable treatment that can be applied to a subject and an outcome that may or may not respond to the treatment. For a causal hypothesis to have 
any significance it is necessary to be able to expose it to a meaningful test. Such tests require that all other determinants of the outcome can be kept constant so that the effect of the treatment can be isolated. Ideally it would be possible to simultaneously observe the same "subject" receiving the treatment as well as not receiving the treatment. This will ensure that everything else is held constant. Of course, it is impossible to observe the same subject in both states simultaneously. We cannot observe the citation rates of a specific scholar being an editorial board member and at the same point in time not being a member of board. However, we can apply a quasi-experimental design that will enable us to test the hypothesis meaningfully. More specifically, we can analyze the citation data for each member of the board before and after entering the board. Using reference samples and applying a difference-indifferences estimator we can identify general tendencies in citation rates as well as tendencies specific to the journal investigated. The difference-in-differences estimator is an estimator that arises in policy analysis with data for two time periods. One version of the estimator applies to independently pooled cross sections and another to panel data sets (Wooldridge, 2009). For further illumination of the methods and their use the reader is referred to Wooldridge (2002).

In order to test the flattery citations hypothesis further we have conducted a study applying the difference-in-difference estimator. The specific method is outlined below. It is followed by a results section, and a discussion and conclusion section in which we discuss the results in relation to various theories about the sociology of science and citation analysis in general.

\section{METHODS}

Since only Laband, Tollison and Karahan (2002) find a positive effect on membership of the editorial board, we proceed to test the hypothesis based on the journals included in their study. Laband, Tollison and Karahan (2002) analyse the editorial screening process in Economics with the objective of "ascertaining how well the process has functioned over time with respect to filtering "bad" papers and selecting "good" papers" (Laband, Tollison and Karahan, 2002: 315). They count the number of times the editors and editorial board members of the American Economic Review were cited in articles published in the journal itself as well as in a pool of documents comprising of articles from Journal of Political Economy and Quarterly Journal of Economics. They report the results from five year intervals from 1985 to 2000 with a one year lag (P326) implying that they have four observations for AER and four for the reference sample. 
In this study we analyse the number of times the editors and editorial board members of the American Economic Review were cited in articles published in the journal itself as well as in a pool of documents comprising of articles from Journal of Political Economy and Quarterly Journal of Economics. We have chosen to analyze citation data five years before membership, the year he or she becomes a member and five years later. In other words years -5 to +5 , leading to a period of 11 years. The first year included in our data is 1984 as is the case in the study by Laband, Tollison and Karahan (2002). However, we expand the publication years included in the study to every board member entering from 1984 to 2004. We cannot include more recent publications than 2004 due to the length of the citation window. In the case of 2004 citations are analysed from 1999 to 2009.

Information on the composition of the board was found in the printed versions of the journal. Using the first issue of each publication year, any new names were registered on the basis of a comparison with the list from the previous year and attributed to year during which they entered. In some cases the role of the scholar in the journal changed from e.g. co-editor to board member. In these cases we only registered the first time he or she entered and not the change of role. This approach resulted in a dataset consisting of 167 editors and editorial board members of which a few had to be excluded as they could not be unambiguously identified in the Social Sciences Citation Index ${ }^{1}$. For cited scholars with common names and several publications, searches brought up hundreds of citations and it was not always possible to distinguish every single citation to confirm whether it was authored by the required author or another with the same last name and initial. The cited author field is not controlled, and consequently attention must be paid to the different forms of names. In these cases, it is possible that some citations were erroneously included or excluded. All citations included in the analysis are delineated to a specific journal and consequently, to a specific discipline and therefore, where there was doubt, the preference was for inclusion rather than exclusion. Hence, citations for these scholars are more likely to have been overestimated than underestimated. However, in a few cases scholars with common names had to be excluded as other scholars with the same last name and initial were found to be cited in the journals included in the study. This procedure resulted in a final data set consisting of 158 editors and board members. In a few cases an individual entered the editorial board more than once during the years

\footnotetext{
${ }^{1}$ The citations are found using Social Sciences Citation Index. Additional citation indexes are superfluous as we only need the publications of the journals in the analysis to be indexed.
} 
observed, and in these cases the individual appears twice in the data set. Appendix 1 provides lists of the editors and editorial boards.

Editors and co-editors are assigned with a dummy variable (Editor=1 if co-editor or editor; otherwise editor $=0$ ). This variable is added to the data set to enable us to analyse any potential effect for editors or co-editors not found for regular members of board or perhaps of a different magnitude. In some cases an individual enters the board as regular member and subsequently becomes a co-editor. In the present study an individual is assigned 1 in the variable if he or she becomes editor or co-editor within the 11 year time period used to analyse the development in citation rates of the individual. Consequently, an individual appearing twice in the data set may be characterised as co-editor or editor in one of the entries and not in the other.

The citations received by each member need to be normalised as journals publish varying numbers of publications each year. Citations to all publications were included in the numerator, however, only the following publication types were included in the denominator: article, review, letter, note. Due to the indexing policy of the citation indexes, citations to all publication types are included in the numerator. During the 31-year-period included in the data set American Economic Review published an average of 182 publications per year (defined as articles, reviews, letters and notes), Journal of Political Economy 54 publications and Quarterly Journal of Economics 48 publications.

The data in the study consists of observations in three groups. One of the groups is exposed to a treatment or experiment in the second period but not in the first period (entering editorial board in the middle of the time period analysed). The second and third group are not exposed to the treatment during either period. In the case where the same units within a group are observed in each time period, the average gain in the control groups is subtracted from the average gain in the treatment group. This removes biases in second period comparisons between the treatment and control groups that could be the result from permanent differences between those groups, as well as biases from comparisons over time in the treatment group that could be the result of trends. All this is integrated into the statistical analysis by introducing the difference-in-differences estimator. Since the work by Ashenfelter and Card (1985), the use of difference-in-differences methods has become widespread in economics as well as in other fields working with social experiments (Cook \& Shadish, 1994; Meyer, 1995; Imbens \& Woolridge, 2009).

\section{RESULTS}


When interpreting the data, one should bear in mind that the difference-in-difference approach requires the identification of a specific intervention against which one should compare the difference in outcomes before and after intervention for a treatment and a control group. A source of spatial and temporal policy variation is necessary to estimate this effect. However, the effect of board membership cannot be expected to be exactly identifiable from year 0 or 1 due to publication lags. Publication lags are generally considerable in economics journals, and the lag can occur in various stages of the process (Yohe, 1980; Trivedi, 1993; Ellison, 2002; Azar, 2007). In 1987 the publication lag was reported to be 65 to 90 weeks on average from submission to publication. Publications in the 1987 issues were consequently submitted in 1985 and 1986 (Ashenfelter, 1988). In 2004 the publication lag was reported to be 83 weeks on average indicating that publications in 2004 were submitted in 2002 or 2003 (Moffitt, 2006). Thus, any flattery citations to an entering board member or editor cannot be expected to be seen before at least 1 to 2 years after entry.

Before analysing the data statistically we present a figure illustrating the average number of citations received by an editor or board member in a publication is these three journals during the years before and after entry. The data has been pooled regardless of the year entering board.

\section{[FIGURE 1]}

Figure 1 Average number of citations per publication to an entering board member (year 0 is the entering year).

First of all we notice that citations to scholars entering the American Economic Review tends to be lower than the number of citations received by these scholars in Journal of Political Economy and Quarterly Journal of Economics. Furthermore, the members of board tend to receive more citations during the entire period and not only in the years after entering the board. Consequently, the increase in citations over time seems to be a general trend.

However, the trends illustrated in this figure are highly dependent on the number of references in the journal. By pure chance, an individual is much more likely to receive 1 out of 100 citations than to 
receive 1 out of 1000. Consequently, the next figure depicts the average number of citations per reference to an entering board member.

\section{[FIGURE 2]}

Figure 2. Average number of citations per reference to an entering board member (year 0 is the entering year).

Figure 2 does seem to indicate a slight increase in citations to board members in American Economic Review whereas such an increase is more difficult to determine for the two control journals, and consequently the difference between figures 1 and 2 could very well be a general increase in the number of references. The mean number of citations received in American Economic Review is generally lower than the two reference samples implying that there is a lower number of references per publication in American Economic Review compared to the two other journals.

The results are reported first in the form of descriptive statistics. Appendix 2 illustrates the differences in the number of citations received in the present study. It is evident that American Economic Review receives noticeably more citations than the two control journals. Consequently, normalisation is necessary. Normalisation is typically calculated using publications as is the case with the journal impact factor. However, alternatives exist that may provide a different picture of impact (see e.g. Nicolaisen $\&$ Frandsen, 2008; Opthof \& Leydesdorff, 2010; Van Raan et al., 2010; Leydesdorff \& Opthof, 2010; Leydesdorff \& Bornmann, 2011). Appendix 3 contains a table with the number publications and references in the three journals during the observed period. It is evident from the table clearly that the three journals have extremely different levels of annual publications as well as references. Consequently, the two different methods of normalisation are included in the statistical analyses below.

The results of the statistical analyses are available in the following table. The table provides an overview of the various models.

[Table 1] 
In order to be able to compare the number of citations in the three different journals we have to use some sort of normalisation, since otherwise any measured effect may be driven purely by different citation patterns or the different number of publications in the journals. Therefore, the citations are normalised using two different approaches. In the first approach, we normalize by the number of publications published in the relevant journal in the relevant year, and in the second approach, we normalize by the total number of citations given in the journal in that year, i.e. the resulting number is the share of citations given to a particular individual that year. As can be seen from Table 1 the results of the two analyses are fundamentally the same and consequently, we report both analyses simultaneously.

These two variations of the normalisation of citations differ according to entering person dummies, i.e. controlling for characteristics of specific persons in the data set. Consequently, two different regressions are being computed: One with person dummies and one without. Again, the results of the now four different analyses are the same and we report both simultaneously.

First of all, the number of citations received in Journal of Political Economy and Quarterly Journal of Economics are lower than the number received in American Economic Review. This is the case both before and after entering board of American Economic Review implying that is not an effect caused by entering board. Secondly, we find no effect of being an editor or co-editor compared to being an ordinary member of board when controlling for individual characteristics, but in the regressions with no person dummies this variable is highly significant reflecting the fact that editors and co-editors of American Economic Review are highly cited regardless of year or journal. Finally and perhaps most importantly, we cannot detect a citation effect of entering board of American Economic Review in any of the specifications, meaning that the present study must reject the hypothesis of flattery citations. ${ }^{2}$

In our search for evidence of the flattery citation effect one might argue that the effect may not exist for regular members of board, but may be measurable for editors and co-editors. Their roles make them more likely to receive flattery citations as their potential influence on the fate of a particular submission is expected to be much greater. Therefore we proceed by testing the flattery citations hypothesis specifically for editors and co-editors and consequently, we select out the subpopulation of our data containing only editors and co-editors of American Economic Review. Appendix 4 illustrates the development in total sums of citations received by board members excluding editors and co-editors.

\footnotetext{
${ }^{2}$ There is a significant publication lag in economics, so one could argue that any flattery effect should not be observed earlier than 1-3 years after entry into the editorial board. For this reason different specifications of the regressions with flattery effect being measured only from year 2 and 3 after entry have been carried out. However, these regressions yield qualitatively identical results to the ones reported in Table 1.
} 
Appendix 5 illustrates the citations received in total by editors and co-editors. There seems to be a greater increase in the citations received by the latter group compared to former but on the other hand the increase predates entering board. We test the citation flattery effect for editors and co-editors statistically. We use the same four models as previously (excluding the binary editor variable) and the results of the statistical analyses are available in Table 2.

[Table 2]

The results of these regressions confirm the overall picture from Table 1, namely that no flattery effect can be found. Surprisingly, the results indicate that editors and co-editors not are cited to a larger extent in American Economic Review than in the other two journals as was the case for the entire population of editorial board members. However, the editors and co-editors of American Economic Review do receive a larger share of citations in their own journal than in Quarterly Journal of Economics.

\section{DISCUSSION AND CONCLUSIONS}

In the early days of science studies it was generally accepted among those who studied the sociology of science that scientific research is governed by a set of rules that are supposed to establish trust in, and guarantee the reliability of, the knowledge created in the research process. This scientific ethos was given its most concise and powerful formulation by the American sociologist Robert King Merton (1910-2003) who defined it in terms of four basic norms known as the CUDOS norms (Merton ([1942] $1973)^{3}$

${ }^{3}$ Communism (later termed "communality") expresses the norm that because all scientific inquiry relies on prior scientists' efforts to some degree, scientific advancements should be added to the pool of communal knowledge. Property rights should be kept to a minimum, and the members of a community must exchange the scientists' claims to intellectual property for recognition and esteem.

Universalism is the principle that truth claims should be subjected to pre-established, impersonal justification criteria that exclude consideration of particularistic criteria such as a scientist's race, nationality, class, or religion.

Disinterestedness conveys the idea that scientists should seek truth objectively, without considering their individual interests.

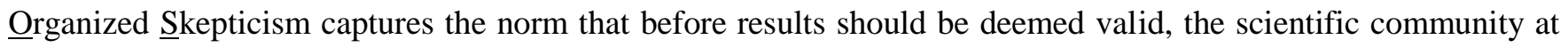
large should examine their reliability. 
Norman Kaplan's article The Norms of Citation Behaviour from 1965 is generally accepted as being the first explicit account of citing as normative behavior (e.g. Small, 1998). Kaplan (1965) held that "footnoting practices" are passed on by word of mouth from professor to student and by an examination of the varying practices of different journals. The major function of footnoting or citing is, according to Kaplan, the reaffirmation of the underlying norms of scientific behavior.

About the same time as Kaplan (1965) issued his belief in citation practices being governed by an implied set of rules, Eugene Garfield (1965: 85) published a list consisting of fifteen reasons why authors cite. The list describes scientists as essentially faithful disciples of the CUDOS norms. Melvin Weinstock, in his article on citation indexes in Encyclopedia of Library and Information Science, offers the exact same list of reasons why authors cite. Weinstock's introduction to the fifteen reasons is interesting as it precisely discloses the most basic assumption of the normative theory of citing:

"Scientific tradition requires that when a reputable scientist or technologist publishes an article, he should refer to earlier articles which relate to his theme. These references are supposed to identify those earlier researchers whose concepts, methods, apparatus, etc. inspired or were used by the author in developing his own article (Weinstock, 1971: 19).

According to the normative theory, failure to give credit where credit is due only rarely occurs. Cole and Cole (1972: 370), for example, state that "sometimes [...] a crucial intellectual forebear to a paper is not cited. The omission is rarely due to direct malice on the part of the author but more often to oversight or lack of awareness [...]. We can assume that omitted citations to less influential work are random in nature [...]". Garfield (1977: 7) agrees declaring that "the vast majority of citations are accurate and the vast majority of papers do properly cite the earlier literature". However, in the next sentence, Garfield admits that this assertion had not been empirically substantiated: "Unfortunately, there has never been a definitive study of this assertion".

The basic assumption of the normative theory of citing was not tested before the 1980's. The pioneers of this work were not adherents of the normative theory, but a group of skeptics including among others the two biologists Michael H. MacRoberts and Barbara R. MacRoberts and the information scientist Terrence A. Brooks. These skeptics challenged the basic assumption that scientists cite their influences (e.g. MacRoberts, 1997, MacRoberts \& MacRoberts, 1984; 1986; 1987a; 1987b; 1988; 1989a; 1989b; 
1996; 2010; Brooks, 1985). Moreover, new lists of citer motives began to surface - lists with motives far from those ideally prescribed by the CUDOS norms (e.g., Thorne, 1977; MacRoberts \& MacRoberts, 1989a; Seglen, 1992; 1997; 1998). These lists portray the citing scientist as basically egoistic, selfinterested, particularistic, and prejudiced - more or less the opposite of the citer characteristics prescribed by the CUDOS norms. This quote from Seglen (1992: 636) is a telling example when compared to the Weinstock quote above:

"Citations are not issued as an entirely fair and objective record of influence, but reflect both the needs and the idiosyncrasies of the citer, including such factors as utility, quality, availability, advertising (self-citation), collaboration or comraderie (in-house citations), chauvinism, mentoring, personal sympathies and antipathies, competition, neglect, obliteration by incorporation, argumentation, flattery, convention, reference copying, reviewing, and secondary referencing”.

That an author sometimes cites to flatter a superior, a potential referee, or the editor of the journal s/he is about to submit an article to has been known and recognized long before P.O. Seglen began to write about it. Garfield has long ago admitted that flattery citations are a real phenomenon:

"In some cases, without doubt, citations may be used for all those sullied purposes that supposedly demean its usefulness for information retrieval: flattery, padding, borrowed distinction, etc.” Garfield (1974: 5)

However, contrary to Seglen, Garfield (1974: 5) maintains that such cases are "the trivial exceptions". The results of our study of four selected LIS journals confirm this (Frandsen \& Nicolaisen, 2010). Although we were not able to unambiguously determine whether flattery citations are actual or not, our results clearly show that any effect of such citations are at best minimal. We therefore concluded that the flattery citation effect appears to be inconsequential for citation analyses made on larger datasets. Yet, our study only concerned four journals representing one discipline. The flattery effect could be bigger and thus more consequential in other journals and disciplines. In order to test the flattery citations hypothesis further, we turned to the field of Economics. In this study we have analysed the number of 
times the editors and editorial board members of the American Economic Review were cited in articles published in the journal itself as well as in a pool of documents comprising of articles from Journal of Political Economy and Quarterly Journal of Economics. Results of the present study support the findings and conclusions of our last study. We find no support for a flattery citation effect in this analysis.

There are probably many good reasons why flattery citations are non-existent or very low in numbers. One of the main reasons is perhaps that the risk of getting exposed as a toady sets a limit to the amount of flattery citations one can possibly bear to put in a scholarly paper. Scholarly papers have (potential) readers. Nevertheless, as discussed by Nicolaisen (2007: 625-629), this is regretfully often neglected by those who argue that citations are mostly given by the author for egoistic and self-promoting reasons.

The scholarly paper has been around for about 350 years and is apparently still doing very well. It is read, quoted, and used by men and women in a great many professions and societies. Would that be the case if the scholarly paper was just a fraud - If citations were mainly given for egoistic and selfpromoting reasons (e.g., flattery)? It is almost impossible to imagine that the scholarly paper could have survived for so long and with such success if that was the case. Scientists would long ago have stopped reading, quoting, and using it. In other words, it would have lead to the collapse of that communication channel. What our results seem to suggest is that flattery citations are non-existent or very low in numbers in the field of Economics, and thus only leave a small and insignificant toll on the scholarly communication system in that discipline. Although these results are in accordance with the results of our study of flattery citations in LIS (Frandsen \& Nicolaisen, 2010), more studies are obviously needed in order to investigate whether our conclusions are valid for all disciplines.

\section{Acknowledgements}

This paper is in part an extension and continuation of a paper presented at the ASIS\&T Annual Meeting in Pittsburgh, PA (2010). The authors gratefully acknowledge the kind advice received in the reviewing process as well as the constructive feedback and suggestions from the audience. 


\section{REFERENCES}

Ashenfelter, O.C. (1988). Report of the Editor American Economic Review. The American Economic Review, 78(2), Papers and Proceedings of the One-Hundredth Annual Meeting of the American Economic Association, 502-510

Ashenfelter, O. and Card, D. (1985). Using the longitudinal structure of earnings to estimate the effect of training programs. Review of Economics and Statistics, 67, 648-660.

Azar, O.H. (2007). The slowdown in first-response times of economics journals: can it be beneficial? Economic Inquiry, 45(1), 179-187.

Brooks, T.A. (1985). Private acts and public objects: An investigation of citer motivations. Journal of the American Society for Information Science, 36(4), 223-229.

Cole, J.R. and Cole, S. (1972). The Ortega hypothesis. Science, 178(4059), 368-375.

Cook, T.D. and Shadish, W. R. (1994). Social Experiments - some developments over the past 15 years. Annual Review of Psychology, 45, 545-580.

Ellison, G. (2002). The Slowdown of the Economics Publishing Process. The Slowdown of the Economics Publishing Process. The Journal of Political Economy, 110(5), 947-993.

Frandsen, T.F. and Nicolaisen, J. (2010). A lucrative seat at the table: Are editorial board members generally over-cited in their own journals?. Proceedings of the ASIS\&T 2010 Annual Meeting.

Garfield, E. (1965). Can citation indexing be automated?. In: Stevens, M.E., Giuliano, V.E. \& Helprin, L.B. (eds.), Statistical Association Methods for Mechanized Documentation, Symposium Proceedings. Washington, DC: National Bureau of Standards, 189-192.

Garfield, E. (1974). Was the Science Citation Index concept inevitable? Current Contents, 50, 5-6.

Garfield, E. (1977). To cite or not to cite: A note of annoyance. Current Contents, 35(August 29), 5-8.

Greenstone, M. and Gayer, T. (2009). Quasi-experimental and experimental approaches to environmental economics. Journal of Environmental Economics and Management, 57(1), 21-44.

Imbens, G.W. and Wooldridge, J.M. (2009). Recent Developments in the Econometrics of Program Evaluation. Journal of Economic Literature, 47(1), 5-86.

Kaplan, N. (1965). The norms of citation behavior: Prolegomena to the footnote. American Documentation, 16(3), 179-184. 
Laband, D.N., Tollison, R.D. and Karahan, G. (2002). Quality control in Economics. Kyklos, 55, 315334.

Leydesdorff, L. and Bornmann, L. (2011). How fractional counting affects the Impact Factor: Normalization in terms of differences in citation potentials among fields of science. Forthcoming in Journal of the American Society for Information Science and Technology.

Leydesdorff, L. and Opthof, T. (2010). Normalization at the field level: fractional counting of citations (Rejoinder), Journal of Informetrics, 4(4), 644-646.

MacRoberts, M. (1997). Rejoinder. Journal of the American Society for Information Science, 48(10), 963.

MacRoberts M.H. and MacRoberts, B.R. (1984). The negational reference: Or the art of dissembling. Social Studies of Science, 14, 91-94.

MacRoberts. M.H. and MacRoberts B.R. (1986). Quantitative measures of communication in science: A Study of the formal level. Social Studies of Science, 16, 151-172.

MacRoberts, M.H. and MacRoberts, B.R. (1987a). Another test of the normative theory of citing. Journal of the American Society for Information Science, 38, 305-306.

MacRoberts, M.H. and MacRoberts, B.R. (1987b). Testing the Ortega hypothesis: Facts and artefacts. Scientometrics, 12, 293-295.

MacRoberts, M.H. and MacRoberts, B.R. (1988). Author motivation for not citing influences: A methodological note. Journal of the American Society for Information Science, 39, 432-433.

MacRoberts, M.H. and MacRoberts, B.R. (1989a). Problems of citation analysis: A critical review. Journal of the American Society for Information Science, 40, 342-349.

MacRoberts, M.H. and MacRoberts, B.R. (1989b). Citation analysis and the science policy arena. Trends in Biochemical Science, 14, 8-10.

MacRoberts, M.H. and MacRoberts, B.R. (1996). Problems of citation analysis. Scientometrics, 36, 435444.

MacRoberts, M.H. and MacRoberts, B.R. (2010). Problems of citation analysis: A study of uncited and seldom-cited influences. Journal of the American Society for Information Science and Technology, 61(1), 1-12. 
Merton, R.K. ([1942] 1973). The normative structure of science. In: Merton, R.K. (ed.), The Sociology of Science: Theoretical and Empirical Investigations. Chicago, IL: University of Chicago Press, 267278.

Meyer, B.D. (1995). Natural and quasi-experiments in economics. Journal of Business \& Economic Statistics, 13(2), 151-161.

Moffitt, R.A. (2006). Report of the Editor: American Economic Review. American Economic Review, http://www.aeaweb.org/aer/2006report.pdf

Nicolaisen, J. (2007). Citation analysis. Annual Review of Information Science and Technology, 41, 609641.

Nicolaisen, J. and Frandsen, T. F. (2008). The Reference Return Ratio . Journal of Informetrics, 2(2), 128-135.

Opthof, T., and Leydesdorff, L. (2010). Caveats for the journal and field normalizations in the CWTS (“Leiden”) evaluations of research performance. Journal of Informetrics, 4(3), 423-430.

Van Raan, A.F.J., Van Leeuwen, T.N., Visser, M.S., Van Eck, N.J., and Waltman, L. (2010). Rivals for the crown: Reply to Opthof and Leydesdorff. Journal of Informetrics, 4(3), in print.

Seglen, P.O. (1992). The skewness of science. Journal of the American Society for Information Science, 43(9), 628-638.

Seglen, P.O. (1997). Citations and journal impact factors: Questionable indicators of research quality. Allergy, 52, 1050-1056.

Seglen, P.O. (1998). Citation rates and journal impact factors are not suitable for evaluation of research. Acta Orthopaedica Scandinavica, 69(3), 224-229.

Small, H. (1998). Citations and consilience in science. Scientometrics, 43(1), 143-148.

Thorne, F.C. (1977). The citation index: Another case of spurious validity. Journal of Clinical Psychology, 33(4), 1157-1161.

Trivedi, P.K. (1993). An Analysis of Publication Lags in Econometrics. Journal of Applied Econometrics, 8(1), 93-100.

Weinstock, N. (1971). Citation indexes. In Kent, A. (ed.), Encyclopedia of Library and Information Science. New York, NY: Marcel Dekker, 16-41. 
Wooldridge, J.M. (2002), Econometric Analysis of Cross Section and Panel Data. Cambridge, MA: MIT Press.

Wooldridge, J.M. (2009). Introductory econometrics: a modern approach. 4th ed. Mason, OH: SouthWestern Cengage Learning.

Yohe, G.W. (1980). Current Publication Lags in Economics Journals. Journal of Economic Literature, 18(3),1050-55. 
APPENDIX 1. LISTING OF EDITORS AND EDITORIAL BOARD MEMBERS

\begin{tabular}{|c|c|c|}
\hline Bennett T. McCallum (co-editor 1987) & 1984 & Alan J. Auerbach \\
\hline Claudia D. Goldin & 1984 & George W. Evans \\
\hline Edgar O. Olson & 1984 & John McMillan \\
\hline George E. Johnson & 1984 & John Roberts \\
\hline Jacob A. Frenkel & 1984 & Joseph G. Altonji \\
\hline John B. Shoven & 1984 & Kyle W. Bagwell \\
\hline John F. Kennan & 1984 & Lorne H. Carmichael \\
\hline Mervyn A. King & 1984 & Robert Boadway \\
\hline Orley Ashenfelter (editor) & 1984 & Roger H. Gordon (co-editor) \\
\hline Paul Krugman & 1984 & Suzanne A. Scotchmer \\
\hline Robert H. Haveman (co-editor) & 1984 & Lawrence J. Christiano \\
\hline Steven Shavell & 1984 & Nancy Gallani \\
\hline Alvin E. Roth & 1985 & R. Preston McAfee (co-editor 1992) \\
\hline Hal R. Varian (co-editor 1987) & 1986 & Robert H. Topel \\
\hline Jo Anna Gray & 1986 & Stephen G. Cecchetti \\
\hline Kenneth Singleton & 1986 & Jeremy Stein \\
\hline Maurice Obstfeld & 1986 & Matthew D. Shapiro (co-editor 1995) \\
\hline Richard Roll & 1986 & Paul L. Joskow \\
\hline Robert H. Porter & 1986 & Paul Romer \\
\hline Barbara J. Spencer & 1987 & R. Mark Isaac \\
\hline David E. M. Sappington & 1987 & Carl E. Walsh \\
\hline James E. Anderson & 1987 & David P. Baron \\
\hline John G. Riley & 1987 & David W. Wilcox \\
\hline Kenneth L. Judd & 1987 & Gary R. Solon \\
\hline Leslie Young & 1987 & Paul R. Milgrom \\
\hline Richard Tresch & 1987 & Rebecca M. Blank \\
\hline Robert S. Smith & 1987 & Robert H. Porter \\
\hline Dale T. Mortensen & 1988 & W. Kip Viscusi \\
\hline Henry S. Farber & 1988 & Dennis N. Epple (co-editor) \\
\hline John D. Wilson & 1988 & Kenneth D. West (co-editor) \\
\hline John H. Kagel & 1988 & Adam B. Jaffe \\
\hline Marjorie A. Flavin & 1988 & Andrew R. Schotter \\
\hline Robert P. Flood & 1988 & Charles C. Brown \\
\hline Timothy F. Bresnahan & 1988 & Curtis R. Taylor \\
\hline Daniel s. Hamermesh & 1989 & Don Fullerton \\
\hline John Y. Campbell (co-editor 1990) & 1989 & Gene M. Grossman \\
\hline Kevin D. Hoover & 1989 & James E. Anderson \\
\hline Leslie Young & 1989 & Jennifer F. Reinganam \\
\hline Paul R. Milgrom (co-editor) & 1989 & Karen K. Lewis \\
\hline Reuben Gronau & 1989 & Nancy L. Rose \\
\hline Robert J. Hodrick & 1989 & Robert A. Moffitt \\
\hline Thomas Romer & 1989 & Roger H. Gordon \\
\hline
\end{tabular}




\begin{tabular}{|c|c|}
\hline Sergio T. Rebelo & 1994 \\
\hline Steven N. Durlauf & 1994 \\
\hline Theodore C. Bergstrom & 1994 \\
\hline Timothy S. Fuerst & 1994 \\
\hline Christina H. Paxson & 1995 \\
\hline David E. M. Sappington & 1995 \\
\hline David H. Romer & 1995 \\
\hline David K. Backus & 1995 \\
\hline Jordy Gali & 1995 \\
\hline Richard E. Romano & 1995 \\
\hline Timothy J. Besley (co-editor 1999) & 1995 \\
\hline Valarie A. Ramey & 1995 \\
\hline Wolfgang Pesendorfer & 1995 \\
\hline Michael D. Woodford & 1996 \\
\hline Allan Drazen & 1997 \\
\hline David N. Weil & 1997 \\
\hline Deidre McCloskey & 1997 \\
\hline Francine D. Blau & 1997 \\
\hline Gordon H. Hanson & 1997 \\
\hline Jeffrey C. Fuhrer & 1997 \\
\hline Martin S. Gaynor & 1997 \\
\hline Peter C. Reiss & 1997 \\
\hline Randall Wright & 1997 \\
\hline Robert W. Staiger & 1997 \\
\hline Susanto Basu & 1997 \\
\hline Charles A. Holt & 1998 \\
\hline David Genesove & 1999 \\
\hline Dennis N. Epple & 1999 \\
\hline Michael H. Riordan & 1999 \\
\hline Michael R. Ransom & 1999 \\
\hline Michelle R. Garfinkel & 1999 \\
\hline Randall Wright & 1999 \\
\hline Robert A. Margo & 1999 \\
\hline Valerie A. Ramey (co-editor) & 1999 \\
\hline Anne C. Case & 2000 \\
\hline Daniel R. Vincent & 2000 \\
\hline Enrique G. Mendoza & 2000 \\
\hline Gilbert E. Metcalf & 2000 \\
\hline Judith A. Chevalier & 2000 \\
\hline M. Scott Taylor & 2000 \\
\hline Peter J. Klenow & 2000 \\
\hline Peter N. Ireland & 2000 \\
\hline
\end{tabular}

Scott Freeman 2000

A. Craig Burnside 2001

Ben S. Bernanke (Editor) 2001

Benjamin E. Hermalin 2001

Carmen M. Reinheart 2001

Daniel Friedman 2001

Joshua D. Angrist 2001

Rachel E. Kranton 2001

Raghuram G. Rajan 2001

Robert C. Feenstra 2001

Stephen Morris 2001

Thomas J. Nechyba 2001

Andrew Atkeson 2002

B. Douglas Bernheim (co-editor) 2002

Charles Engel 2002

Colin Camerer 2002

David Card (co-editor) 2002

Donald Davis 2002

Hilary Hoynes 2002

Ilya Segal 2002

James B. Rebitzer 2002

Patrick Kehoe 2002

R. Preston McAfee 2002

Richard Rogerson (co-editor) 2002

Susan Athey 2002

Giovanni Maggi 2003

Kenneth Wolpin 2003

Lones Smith 2003

Thomas Lemieux 2003

Janice C. Eberly 2004

Jeremy Bulow (co-editor) 2004

John A. List 2004

John C. Heaton 2004

Judith Chevalier (co-editor) 2004

Mark Bils 2004

Mark Gertler (co-editor) 2004

Robert A. Moffitt (editor) 2004

Simon Gilchrist 2004

Stephen Coate 2004

Steven Tadelis 2004

Thomas N. Hubbard 2004 


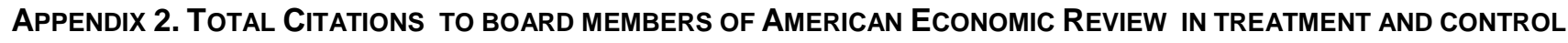
GROUPS

[APPENDIX 2] 
APPENDIX 3. PUblicATIONS AND REFERENCES IN TREATMENT AND CONTROL GROUPS

\begin{tabular}{lrrrrrr}
\multicolumn{5}{c}{ Publications } & & \multicolumn{3}{r}{ References } & & \\
2009 & AER & JPE & QJE & AER & JPE & QJE \\
2008 & 197 & 31 & 46 & 2342 & 1593 & 694 \\
2007 & 185 & 31 & 44 & 2358 & 1453 & 1538 \\
2006 & 185 & 32 & 44 & 2455 & 1272 & 796 \\
2005 & 185 & 37 & 40 & 2522 & 1331 & 814 \\
2004 & 175 & 42 & 40 & 2926 & 1176 & 868 \\
2003 & 167 & 57 & 41 & 2887 & 1241 & 874 \\
2002 & 178 & 42 & 41 & 2960 & 1245 & 1237 \\
2001 & 181 & 44 & 42 & 2708 & 1631 & 819 \\
2000 & 179 & 50 & 43 & 2418 & 1569 & 930 \\
1999 & 154 & 55 & 40 & 2625 & 1469 & 814 \\
1998 & 161 & 43 & 42 & 2819 & 1605 & 845 \\
1997 & 149 & 51 & 39 & 3073 & 1772 & 1100 \\
1996 & 163 & 46 & 41 & 2820 & 1479 & 1302 \\
1995 & 170 & 50 & 40 & 3303 & 1385 & 1294 \\
1994 & 186 & 52 & 44 & 3034 & 1290 & 1101 \\
1993 & 174 & 49 & 48 & 3414 & 1292 & 1159 \\
1992 & 197 & 50 & 56 & 3078 & 1379 & 1120 \\
1991 & 181 & 58 & 59 & 3126 & 1444 & 1262 \\
1990 & 183 & 62 & 54 & 2469 & 1386 & 1418 \\
1989 & 185 & 71 & 45 & 3484 & 1282 & 1310 \\
1988 & 182 & 64 & 49 & 3461 & 1787 & 1422 \\
1987 & 156 & 70 & 50 & 3472 & 1299 & 1978 \\
1986 & 206 & 72 & 50 & 3825 & 1548 & 2053 \\
1985 & 209 & 63 & 70 & 4347 & 1474 & 1647 \\
1984 & 209 & 58 & 52 & 4331 & 1418 & 1574 \\
1983 & 192 & 56 & 58 & 3677 & 1782 & 1554 \\
1982 & 189 & 68 & 40 & 4094 & 1447 & 1752 \\
1981 & 193 & 68 & 45 & 1231 & 1658 \\
1980 & 194 & 79 & 102 & 4897 & 1142 & 1772 \\
1979 & 186 & 87 & 48 & 1355 & 2065 \\
& & & & 1094 & 1985
\end{tabular}




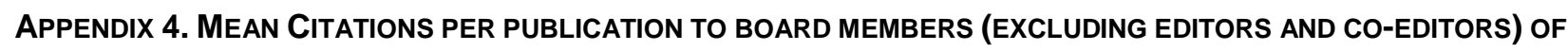
AMERICAN ECONOMIC REVIEW IN TREATMENT AND CONTROL GROUPS

\section{[APPENDIX 4]}

APPEndiX 5. MeAn CitATIONS PER PUblication to boARD MEMBERS (INCLUDING ONLY EDITORS AND CO-EDITORS) OF AMERICAN ECONOMIC REVIEW IN TREATMENT AND CONTROL GROUPS

\section{[APPENDIX 5]}

